\title{
Implementing structured model of clinical handover (SHARED): Its influence on nurses' satisfaction
}

\author{
Sohair Mabrouk Mohammed, Sanaa Moustafa Safan* \\ Nursing Administration, Faculty of Nursing, Menoufia University, Egypt
}

Received: October 8, 2018

Accepted: November 8, 2018

Online Published: November 19, 2018

DOI: $10.5430 / \mathrm{cns} . \mathrm{v} 7 \mathrm{n} 1 \mathrm{p} 71$

URL: https://doi.org/10.5430/cns.v7n1p71

\begin{abstract}
Objective: Clinical handover is acting an important role which nurses are usually involved numerous times in daily working for providing patient care. In spite of the importance of clinical handover, there is no standardized handover practice in our healthcare settings. This study aimed to explore the effect of implementing a structured model of clinical handover (SHARED), and its influence on nurses' satisfaction.

Methods: Design: The quasi-experimental design was utilized. Settings: Conducted at Menoufia University Hospitals at inpatient departments/units. Subjects: A convenient sample of 167 staff nurses who had at least a year of experience and accept to participate in this study. Tools: Tool I, Handover Knowledge Questionnaire; Tool II: clinical handover questionnaire; and Tool III, nurses' satisfaction questionnaire.

Results: Nurses' levels of total knowledge regarding practices of the current clinical handover were poor at pre-implementation and improved after implementation of the structured model as SHARED. Additionally, there was an improvement of clinical handover attitude after implementation of a SHARED framework among studied subjects and had a good level of attitude than pre-implementation phases.

Conclusions: There was the highest level of nurses' satisfaction regarding clinical handover practice at the post-implementation of SHARD model than pre-implementation.

Recommendations: Ongoing educational sessions for nurses and periodic refresher training courses should be provided in order to keep nurses updating knowledge and practice regarding structured and standardized handover models.
\end{abstract}

Key Words: Structured model, Clinical shift handover, Nurses satisfaction

\section{INTRODUCTION}

On a day-to-day function, in each healthcare setting, the obligation for the care of patients is reassigned among healthcare personnel. The announcement of client information to the following caregiver can be recognized as "handover". Handover is an important process during which clinicians share information, as well as exchange authority and main accountability for patient care. The assignment of care requests the handover of information about the nature of the patient's complaint and full requirements for more exploration and treatment. ${ }^{[1]}$

The handover includes that patient information, responsibility, and authority is moved from one of caregivers to advancing or new staff. Three factors that anticipate handover quality are recognized: information transfer, mutual understanding, and at work atmosphere. Within nursing, the giving of the report has been factually recognized and is accepted as a part of the nursing tradition and culture. ${ }^{[2]}$ A systematic

\footnotetext{
*Correspondence: Sanaa Moustafa Safan; Email: sanaa_safan@yahoo.com; Address: Nursing Administration, Faculty of Nursing, Menoufia University, Egypt.
} 
review of the current information to define handover features and the ensuing effect on safety results was conducted. Handover results were defined as every activity that happens after achievement of the handover or related to patients who are handed off for their treatment. ${ }^{[3]}$

Clinical handover methods need to be designed and documented. This safeguards that all members identify the purpose of the handover, the vital information and documentation they need to communicate. Handover involves the transmission of standard information between clinicians within a discipline, from one discipline to another, and between wards or departments within a health facility. Handover should happen at the change of the shift, from one ward to another ward or department, at patient relocation to another facility, on patient discharge, and when a patient's condition merits it. ${ }^{[4]}$ Poor communication handovers have resulted in adverse actions, delays in treatment, severances that influence efficiencies and effectiveness, and low patient and healthcare worker satisfaction. ${ }^{[5]}$

Standardizing the process to safeguard exact and relevant information interchange through the occasion for illustrative demands has been identified as a vital for improving patient safety. So far, there is a lack of a standardization process. The lack of a standardization process for "handovers" makes it hard to control. ${ }^{[3]}$ Obstacles and organizers to clinical handovers are well-known. However, indicators for the greatest practice are not obvious. There is some research available to inform on that issue. Nurse reports have been known as a "ritual" that includes difficult, cognitively powerful actions that are predisposed by the setting and culture of the unit where the nurse is working. ${ }^{[3]}$

So, the structured model of clinical handover (SHARED) framework for clinical handover outlines and explains the essential components of clinical handover. These components are essential for the provision of safe and effective healthcare. The SHARED framework assists clinicians to participate in comprehensive, appropriate and safe clinical communication irrespective of clinical. ${ }^{[6]}$ Components are important for the providing of harmless and effective healthcare. This structured model, announced in August 2011, and previously reported by Klim et al., ${ }^{[7]}$ contains the subsequent features: (1) a systematic method; (2) conducted at the bedside; (3) involvement of the patient and/or relative; (4) showing of patient charts during handover; and (5) a preliminary group handover for general information about unbalanced patients and overall status of the department. The model also highlights nursing care requirements and the treatment and disposition plan and includes stimuli for significant nursing care basics (medication chart, vital signs, fluid balance, vital signs). The notepads, individual forms in a pad for single use, were planned to provide prompts for the nurse to inform the nurse-in-charge or treating doctor of the deteriorating patient. ${ }^{[8]}$

This SHARED framework contained five attributes for current clinical handover. The first attribute is called face to face communication and is the good means for safeguarding responsibility that patient care is handed over correctly. Face communication helps handover to be collaborating and a double way process where the occasion for questioning and confirmation is allowed between the giver and receiver of the information. A second attribute is the allocation of enough time for the handover and communication of upto-date information is essential. ${ }^{[9]}$ A third attribute is the vital use of a shared language and a standardized method mainly for sharing critical information. The correction of using common language and a standardized method "under routine conditions" helps "health specialists to regularize and form their communication in an approach that confirms better understanding", mainly when time, pressure, and urgency applies precise and reliable information exchange to safeguard patient safety. A fourth attribute called forms and checklists are very important as they can be approved from caregiver to receiver and trailed in a patient's chart. And the fifth attribute is called place of the narrative understanding and representation of a clinical situation in combination with a formalized method and minimum data set for clinical communication. ${ }^{[10]}$

Nurses referred to bedside clinical handover as the best methods of communication between nurses, patients and family members. Bedside clinical handover allowing nurses to check their patients and explain any doubts to confirm the continuity of care. Nurse's needs handover to be in a structured manner, to see the patient, and transfer of the important patient information during handover to the incoming nurses. $^{[11]}$

\subsection{Significance of the study}

Patient handovers comprise a process of transitory information, responsibility and mechanism from sender to the receiver during care transitions. Useless handovers have severe significant outcomes in wrong treatments, delays in diagnosis, longer patient stays, medication errors, patient falls and patient deaths. Nowadays, essential components of nurse-nurse handovers have not been known and a lack of identification is significant in moving towards a standardized method for nurse-nurse handovers. Moreover, during clinical supervision, it was observed that the handover process was done randomly (not follow a systematic approach or method), there were no formal and standardized methods of transferring patient information, and reports were subjective 
(semi-structured format based on the patient sheet). So this study was conducted out to explore the effect of implementing a SHARED and its influence on nurses satisfaction

\subsection{Aim of the study}

This study aimed to explore the effect of implementing a SHARED and its influence on nurses satisfaction.

\subsection{Research hypotheses}

(1) There will be an insufficient knowledge and improper attitude regarding clinical handover among the study subjects.

(2) There will be an improvement of clinical handover knowledge and attitude post implementation of the structured model among studied subjects.

(3) There will be an increased level of staff nurses' satisfaction after implementing a SHARED.

\section{Methods}

\subsection{Design}

The quasi-experimental research design was utilized.

\subsection{Setting}

The study was conducted at Menoufia University Hospitals at inpatient departments/units (Hemodialysis, Medicine, Oncology and Obstetric units).

\subsection{Subjects}

A convenient sample of 167 staff nurses who had at least a year of experience and accepted to participate in the study from above-mentioned departments at Menoufia University Hospital.

\subsection{Tools}

To achieve the purpose of this study the following tools were used.

Tool I: Clinical Handover Knowledge Questionnaire. This tool consisted of two parts:

Part I: Contains socio-demographic characteristics of the study subjects such as age, qualification, years of experience and department.

Part II: Clinical Handover Knowledge Questionnaire was developed by the researchers after reviewing the related literature $^{[11]}$ to assess their knowledge about actual handover practices. It included 15 multiple-choice questions: Handover definition and related concepts (3 questions), importance and benefits of handover (3 questions), components of handover and communication competence (3 questions) methods and structure of handover (3 questions), and handover communication tools (3 questions). With scoring (one) for the right answer and (zero) for the incorrect answer. With scoring that nurses' level of knowledge was determined as follow: high knowledge level $>75 \%$, moderate knowledge level ranged from $60 \%-75 \%$ and low knowledge level $<60 \%$.

Tool II: The clinical handover attitude questionnaire: This tool was adapted from Kerr et al., ${ }^{[8]}$ O'connell et al. ${ }^{[13]}$ It consisted of 21 items to assess nurses attitude of practicing clinical handover through a three-point Likert scale: (1) disagree, (2) neutral and (3) agree. Items such as "Information was presented in a systematic and organized way" and "The way in which information was provided to me was easy to follow" were asked. Data were collected through two phases: pre and post implementation of the SHARED. With scoring as follows, $60 \%$ and more were considered the good attitude of practicing clinical handover, and less than $60 \%$ were considered the poor attitude of practicing clinical handover.

Tool III: Nurses' satisfaction questionnaire was used to assess nurses' satisfaction related to the handover process (prior, and after implementation of a structured model of handover). This questionnaire has of 23 items related to three dimensions of nurses satisfaction. The first dimension called prior to clinical handover ( 7 items). The second dimension is called during hander over (13 items) and the third dimension called after handover (3 items).

\subsection{Scoring system}

The respondents were asked to indicate their satisfaction or dissatisfaction with the questionnaire statements using scale (1-unsatisfied and 2-satisfied). Therefore the maximum possible scores were 46 . With scoring as follows, $70 \%$ and more were considered satisfied, became unsatisfied, if they had less than $70 \%$. This tool carried out before and after implementation of structured model (SHARED).

\subsection{The validity of the instruments}

Tools were tested to assess face and content validity through experts' opinions, which were assessed through a group of five experts in the field of nursing administration. They were also asked to judge the items for suitability, fullness, and clarity.

\subsection{Reliability of the instruments}

Test-retest reliability was realistic by the researcher for testing the internal consistency of the tool. It was done by giving the same tools to the same applicants under similar circumstances on two or more times. Scores from recurrent testing were compared. The Cronbach's coefficient alpha for the handover knowledge questionnaire was 0.94, clinical handover questionnaire was 0.79 , and nurse satisfaction questionnaire 
was 0.95 .

\subsection{Pilot study}

A pilot study was carried out on $10 \%$ of the study subjects (17) who were not included in the main study subject pool in order to test the clarity, validity, and reliability. Necessary modifications and clarifications of some questions were made to have more appropriate tools for data collection. Some questions and items were omitted, added or rephrased and then the final forms were developed. The average time needed to be completed.

\subsection{Fieldwork}

Preparation of data collection tools was carried out over a period of four months from the first of April to the end of July 2016. An oral consent was taken from study subjects. The questionnaires were distributed during nurse's work hours (morning and afternoon shifts) at the available hospital after two or three hours of her starting shift to confirm that patient care was provided. The data collected through 3 days/week, the nurses were taken according to their units workload. The usual time required to complete the questionnaires; the first tool ranged between (15-20 minutes), the second tool ranged between (10-15 minutes), and the third tool (10-20 minutes)

\subsection{Administrative and ethical considerations}

Written approval from the Medical and Nursing Directors of Menoufiya University Hospitals to conduct the study was obtained prior starting data collection from the nurses. The researcher announced herself to them, clarified the objectives of the study, and informed them that their information would be confidential and used for the single purpose of the study. Additionally, each subject was informed about the right to accept or refuse to participate in the study. Their verbal consent was taken.

\subsection{Statistical analysis}

The data collected were analyzed by SPSS version 20 on IBM compatible computer. Quantitative data were expressed as mean and standard deviation and analyzed by applying student $t$-test for comparison of two groups of normally distributed variables. Qualitative data were stated as number and percentage and analyzed by applying chi-square test. paired samples test was applied for comparison between the quantitative data at interval for the same group at two sessions. $\mathrm{McNemar}$ tests were used in the present study for comparing differences in proportions when values are resulting from paired (non independent) groups. Significance was adopted at $p<.05$ for interpretation of results of tests of significance.

\subsection{Procedure}

Before implementing the structured handover model, the researcher done assessment of the actual handover carried out by nurses and identifies the positive and negative point to assess need for standardized handover through clinical handover knowledge questionnaire. The process was carried out by the nurse-in-charge of the leaving shift to those on the incoming shift. Shift-to-shift nursing handover commonly occurs two times per day: morning, and afternoon. Primary data advocated that there were problems with the comprehensiveness of nursing documentation and various parts of the nursing care. In another study, nurses stated that previous handover structures threatened continuity of care. Thus the SHARED structured of nursing handover was established and introduced as a deliberate approach to improve the quality of clinical handover, nursing practice and documentation in the organization in which this study was conducted. The notepads stimulated nurses to use a standardized approach to supplying the handover, which caused stress on nursing care needs, the treatment and disposition plan, and stimuli for vital nursing care components (medication chart, vital signs, fluid balance, vital signs).

The structured model called the SHARED; provided a standardized method that cleared the lowest dataset. Improvements in accuracy and appropriateness of information were noted $^{[12]}$ (see Table 1).

\section{RESULTS}

Table 2 presents socio-demographic characteristics of the studied subjects. As indicated in this table, the mean age of studied nurses were $(31.6 \pm 6.48)$ and the majority of the studied subjects $(95.8 \%)$ were from 20 to less than 40 years old. Furthermore, the majority of subjects (72.4) had from 10-20 years of clinical experience with a mean of approximately 11 years $(11.3 \pm 6.65)$. Regarding qualifications, the highest percentage of the studied subjects (41.3\%) had diploma in nursing. And also the majority of subjects $(38.3 \%)$ were from the department of medicine.

Table 3 illustrates distribution of nurses' levels of clinical handover knowledge pre and post-implementation phases. It was observed that levels of studied subjects' total knowledge were significantly improved from post-implementation to pre at $p \leq .05$. And also, level of clinical hand over knowledge was low $(76.6 \%)$ pre-implementation of SHARED. Otherwise, the level of clinical hand over knowledge was high (74.8) post-implementation of SHARED.

Table 4 indicates the knowledge of studied subjects about the handover process pre and post-implementation of the model. As shown in the table, a method of handover changed at pre 
$\&$ post-implementation of the model, and all nurses used the oral and written method. Handover takes more time 1620 pre-implementation, but after the implementation phase, it takes less time. Regarding the site of handover carried out at nurse room and counter (station) at the study phases incomplete sentence. Additionally, there was a significant improvement of handover process after implementation of the model.

Table 1. SHARED handover structured model

\begin{tabular}{|ll|}
\hline $\mathrm{S}$ & $\begin{array}{l}\text { Situation } \\
\text { Reason for admission/phone call/change in condition; diagnosis specific information }\end{array}$ \\
$\mathrm{H}$ & $\begin{array}{l}\text { History } \\
\text { Medical/surgical/psychosocial/recent treatment/responses and events }\end{array}$ \\
$\mathrm{A}$ & $\begin{array}{l}\text { Assessment } \\
\text { Results/blood tests/X-rays scans/observations/severity of condition }\end{array}$ \\
$\mathrm{R}$ & $\begin{array}{l}\text { Risk } \\
\text { Allergies/infection control/literacy/cultural/drugs/skin integrity/mobility/falls }\end{array}$ \\
$\mathrm{E}$ & $\begin{array}{l}\text { Expectation } \\
\text { Expected outcomes; plan of care; timeframes; discharge plan; escalation } \\
\text { Documentation }\end{array}$ \\
D & \begin{tabular}{l} 
Progress notes; care path; relevant electronic health record/database \\
\hline
\end{tabular}
\end{tabular}

Table 2. Distribution of socio-demographic characteristics of studied subjects $(\mathrm{n}=167)$

\begin{tabular}{lll}
\hline Socio-demographic characteristics & No. & \% \\
\hline Age & 0 & 0.00 \\
- <20 years & 80 & 47.9 \\
- 20-30 years & 80 & 47.9 \\
- 30-40 years & 7 & 4.2 \\
- $\geq 40$ years & $31.6 \pm 6.48$ \\
Mean $\pm S D$ & \multicolumn{2}{|}{} \\
Years of experience & 20 & 12.0 \\
- <5 years & 26 & 15.6 \\
- 5-10 years & 121 & 72.4 \\
- 10-20 years & $11.3 \pm 6.65$ \\
Mean $\pm S D$ & \multicolumn{2}{|}{} \\
Qualification & 32 & 19.2 \\
- Bachelor degree in nursing & 69 & 41.3 \\
- Diploma & 66 & 39.5 \\
- Associated degree in nursing & \multicolumn{2}{|c}{} \\
Departments/units & 64 & 38.3 \\
- Medicine & 33 & 19.8 \\
- Hemodialysis & 44 & 26.3 \\
- Obestetric & 26 & 15.6 \\
- Oncology & & \\
\hline
\end{tabular}

Table 5 displays handover attitude throughout pre and postimplementation phases among studied subjects. The table indicated that statistically significant improvement of the studied subjects regarding the most items of clinical handover pre and post-implementation phases at $p \leq .05$. And also, nurses reported that finding information in a systematic and organized way (pre: $32.3 \%$; post: $53.8 \% ; p<.001$ ) and using effective communication skills during handover (pre: $42.5 \%$; post: $77.8 \% ; p<.001)$.
Table 6 displays handover attitude throughout pre and postimplementation phases among studied subjects. The table indicated the statistically significant improvement of the studied subjects regarding the most items of clinical handover pre and post-implementation phases at $p \leq .05$. And also, nurses reported that information received was up to date (pre: $0.0 \%$; post: $77.8 \% ; p<.001)$ and that during handover discussions, patients had the opportunity to participate and/or listen (pre: $1.2 \%$; post: $31.2 \% ; p<.001)$. As a result of handover, I have a clear understanding of the plan for the patient/s (pre: $15 \%$; post: $65.3 \% ; p<.001)$ at an increased rate after implementation of the structured handover approaches. Respondents were less likely to report that "observations of the important vital signs are repeatedly absent from nursing handover" (pre: $65.3 \%$; post: $34.2 \% ; p<.001)$ after implementation of the structured handover approach.

Figure 1 shows handover attitude throughout pre and postimplementation phases among studied subjects. It was observed that there was an improvement of clinical handover attitude post-implementation of SHARED framework among studied subjects (74.80\%) and had a good level of clinical handover attitude (34.40\%) than pre-implementation phases.

Table 7 shows mean score of nurse satisfaction about clinical handover practice pre and post-implementation phases. As indicated from the table, there was highly statistically significant difference in relation to the mean score of nurse Satisfaction of clinical handover throughout the study phases. The mean score $(33.1 \pm 4.21)$ during the handover process was improved at the post-implementation of structured model (SHARED framework) than pre-phase. Respectively the total mean score $(58.2 \pm 3.21)$ of nurse satisfaction was improved at the post than pre-implementation of a SHARED. 
Table 3. Distribution of nurses' levels of clinical handover knowledge pre and post implementation phases $(\mathrm{n}=167)$

\begin{tabular}{|c|c|c|c|c|c|c|}
\hline \multirow{2}{*}{ Studied variables } & \multicolumn{2}{|c|}{ Pre-implementation } & \multicolumn{2}{|c|}{ Post-implementation } & \multirow{2}{*}{ McNemar test } & \multirow{2}{*}{$p$ value } \\
\hline & No. & $\%$ & No. & $\%$ & & \\
\hline Knowledge of handover & & & & & 88.6 & $.001^{* * *}$ \\
\hline - High & 29 & 17.4 & 125 & 74.8 & & \\
\hline - Moderate & 10 & 6.0 & 34 & 20.4 & & \\
\hline - Low & 128 & 76.6 & 8 & 4.8 & & \\
\hline
\end{tabular}

Note. ${ }^{* *}$ Highly significant

Table 4. Levels of knowledge of studied subjects about clinical handover practice (process) pre and post-implementation of the model $(\mathrm{n}=167)$

\begin{tabular}{|c|c|c|c|c|c|c|}
\hline \multirow{2}{*}{ Studied variables } & \multicolumn{2}{|c|}{ Pre-implementation } & \multicolumn{2}{|c|}{ Post-implementation } & \multirow{2}{*}{ McNemar test } & \multirow{2}{*}{$p$ valu } \\
\hline & No & $\%$ & No & $\%$ & & \\
\hline Method of handover & & & & & -- & -- \\
\hline - Oral and written & 167 & 100.0 & 167 & 100.0 & & \\
\hline - Oral & 00.0 & 00.0 & 00.0 & 00.0 & & \\
\hline - Witten & 00.0 & 00.0 & 00.0 & 00.0 & & \\
\hline - Sound recorded & 00.0 & 00.0 & 00.0 & 00.0 & & \\
\hline Time of handover & & & & & 15.8 & $.001^{* *}$ \\
\hline - $10-15$ & 26 & 15.6 & 140 & 83.8 & & \\
\hline - $16-20$ & 139 & 83.2 & 27 & 16.2 & & \\
\hline - $21-30$ & 2 & 1.20 & 0 & 0.00 & & \\
\hline Site of handover & & & & & 14.3 & $.002^{* *}$ \\
\hline - Beside patients & 26 & 26.3 & 11 & 6.60 & & \\
\hline - Nurses counter(station) & 44 & 19.8 & 47 & 28.1 & & \\
\hline - Nurse room & 33 & 15.6 & 19 & 11.4 & & \\
\hline - Nurse room and counter(station) & 64 & 38.3 & 90 & 53.9 & & \\
\hline
\end{tabular}

Note. ${ }^{* *}$ Highly significant

Table 5. Nurses' handover attitude throughout pre and post-implementation phases among studied subject $(\mathrm{n}=167)$

\begin{tabular}{|c|c|c|c|c|c|c|c|c|}
\hline \multirow{3}{*}{ Handover Attitude Items } & \multicolumn{6}{|c|}{ Studied staff nurses } & \multirow{3}{*}{$\begin{array}{l}\text { McNemar } \\
\text { test }\end{array}$} & \multirow{3}{*}{$p$ value } \\
\hline & \multicolumn{3}{|c|}{ Pre-implementation, No. (\%) } & \multicolumn{3}{|c|}{ Post-implementation, No. (\%) } & & \\
\hline & Agree & Neutral & Disagree & Agree & Neutral & Disagree & & \\
\hline $\begin{array}{l}\text { 1. During handover, I provided with sufficient } \\
\text { information about patients in my care. }\end{array}$ & $78(46.7)$ & $\begin{array}{c}71 \\
(42.5)\end{array}$ & $\begin{array}{c}18 \\
(10.8)\end{array}$ & $\begin{array}{c}84 \\
(50)\end{array}$ & $\begin{array}{c}70 \\
(42.9)\end{array}$ & $\begin{array}{c}13 \\
(7.1)\end{array}$ & 1.04 & .595 \\
\hline $\begin{array}{l}\text { 2. During handover, I provided with suitable } \\
\text { information about all patients in the unit. }\end{array}$ & $53(31.7)$ & $\begin{array}{c}61 \\
(36.5)\end{array}$ & $\begin{array}{c}53 \\
(31.7)\end{array}$ & $\begin{array}{c}56 \\
(33.5)\end{array}$ & $\begin{array}{c}57 \\
(34.1)\end{array}$ & $\begin{array}{c}54 \\
(32.4)\end{array}$ & 0.230 & .892 \\
\hline 3. Handover was too lengthy. & $28(16.8)$ & $\begin{array}{c}85 \\
(50.9)\end{array}$ & $\begin{array}{c}54 \\
(32.3)\end{array}$ & $\begin{array}{c}31 \\
(18.5)\end{array}$ & $\begin{array}{c}53 \\
(31.8)\end{array}$ & $\begin{array}{c}83 \\
(49.7)\end{array}$ & 13.7 & $.001^{* *}$ \\
\hline $\begin{array}{l}\text { 4. Information was presented in a systematic and } \\
\text { organized way. }\end{array}$ & $54(32.3)$ & $\begin{array}{c}87 \\
(52.1)\end{array}$ & $\begin{array}{c}26 \\
(15.6)\end{array}$ & $\begin{array}{c}90 \\
(53.8)\end{array}$ & $\begin{array}{c}51 \\
(30.5)\end{array}$ & $\begin{array}{c}26 \\
(15.6)\end{array}$ & 18.4 & $.001^{* *}$ \\
\hline 5. Important information was not given to me. & $42(25.1)$ & $\begin{array}{c}75 \\
(44.9)\end{array}$ & $\begin{array}{c}50 \\
(29.9)\end{array}$ & $\begin{array}{c}44 \\
(26.3)\end{array}$ & $\begin{array}{c}75 \\
(44.9)\end{array}$ & $\begin{array}{c}48 \\
(28.8)\end{array}$ & 0.090 & .957 \\
\hline $\begin{array}{l}\text { 6. During patient handover, I was given irrelevant } \\
\text { and/or inappropriate information. }\end{array}$ & $33(19.8)$ & $\begin{array}{c}73 \\
(43.7)\end{array}$ & $\begin{array}{c}61 \\
(36.5)\end{array}$ & $\begin{array}{c}33 \\
(19.8)\end{array}$ & $\begin{array}{c}73 \\
(43.7)\end{array}$ & $\begin{array}{c}61 \\
(36.5)\end{array}$ & -- & -- \\
\hline $\begin{array}{l}\text { 7. The charts were available during handover to } \\
\text { clarify information provided to me. }\end{array}$ & $42(25.1)$ & $\begin{array}{c}101 \\
(60.5)\end{array}$ & $\begin{array}{c}24 \\
(14.4)\end{array}$ & $\begin{array}{c}86 \\
(51.5)\end{array}$ & $\begin{array}{c}56 \\
(33.5)\end{array}$ & $\begin{array}{l}25 \\
(15)\end{array}$ & 28.0 & $.001^{* *}$ \\
\hline $\begin{array}{l}\text { 8. Handover includes chart e.g. drug chart, vital } \\
\text { signs. }\end{array}$ & $92(55.1)$ & $\begin{array}{c}75 \\
(44.9)\end{array}$ & $\begin{array}{c}0 \\
(0.00)\end{array}$ & $\begin{array}{c}93 \\
(55.6)\end{array}$ & $\begin{array}{c}74 \\
(44.4)\end{array}$ & $\begin{array}{c}0 \\
(0.00)\end{array}$ & 0.01 & .912 \\
\hline $\begin{array}{l}\text { 9. Ways of provided information to me was easy to } \\
\text { follow. }\end{array}$ & $57(34.1)$ & $\begin{array}{c}73 \\
(43.7)\end{array}$ & $\begin{array}{c}37 \\
(22.2)\end{array}$ & $\begin{array}{c}69 \\
(41.3)\end{array}$ & $\begin{array}{c}46 \\
(27.5)\end{array}$ & $\begin{array}{c}52 \\
(31.1)\end{array}$ & 9.80 & $.007^{* *}$ \\
\hline $\begin{array}{l}\text { 10. During handover, excessive noise can lead to } \\
\text { unable to keep my mind focused. }\end{array}$ & $52(31.1)$ & $\begin{array}{c}46 \\
(27.5)\end{array}$ & $\begin{array}{c}69 \\
(41.3)\end{array}$ & $\begin{array}{c}52 \\
(31.1)\end{array}$ & $\begin{array}{c}46 \\
27.5)\end{array}$ & $\begin{array}{c}69 \\
(41.3)\end{array}$ & -- & -- \\
\hline $\begin{array}{l}\text { 11. Using effective communication skills during } \\
\text { handover. }\end{array}$ & $71(42.5)$ & $\begin{array}{c}0 \\
(0.00)\end{array}$ & $\begin{array}{c}96 \\
(57.5)\end{array}$ & $\begin{array}{c}130 \\
(77.8)\end{array}$ & $\begin{array}{c}34 \\
(20.4)\end{array}$ & $\begin{array}{c}3 \\
(1.80)\end{array}$ & 138.0 & $.001^{* *}$ \\
\hline
\end{tabular}

Note. ${ }^{* *}$ Highly significant 
Table 6. Nurses' handover attitude throughout pre and post-implementation phases among studied subject $(\mathrm{n}=167)$

\begin{tabular}{|c|c|c|c|c|c|c|c|c|}
\hline \multirow{3}{*}{ Handover Attitude Items } & \multicolumn{6}{|c|}{ Studied staff nurses } & \multirow{3}{*}{$\begin{array}{l}\text { McNemar } \\
\text { test }\end{array}$} & \multirow{3}{*}{$p$ value } \\
\hline & \multicolumn{3}{|c|}{ Pre-implementation, No. (\%) } & \multicolumn{3}{|c|}{ Post-implementation, No. (\%) } & & \\
\hline & Agree & Neutral & Disagree & Agree & Neutral & Disagree & & \\
\hline $\begin{array}{l}\text { 12. Handover was disturbed by patients, and } \\
\text { health professionals. }\end{array}$ & $\begin{array}{c}68 \\
(40.7)\end{array}$ & $\begin{array}{c}74 \\
(44.3)\end{array}$ & $\begin{array}{c}25 \\
(15.0)\end{array}$ & $\begin{array}{c}96 \\
(57.5)\end{array}$ & $\begin{array}{c}29 \\
(17.4)\end{array}$ & $\begin{array}{c}42 \\
(25.1)\end{array}$ & 28.7 & $.001^{* *}$ \\
\hline 13. Receiving information was up to date. & $\begin{array}{c}0 \\
(0.00)\end{array}$ & $\begin{array}{c}130 \\
(77.8)\end{array}$ & $\begin{array}{c}37 \\
(22.2)\end{array}$ & $\begin{array}{c}130 \\
(77.8)\end{array}$ & $\begin{array}{c}36 \\
(21.6)\end{array}$ & $\begin{array}{c}1 \\
(0.59)\end{array}$ & 217.3 & $.001^{* *}$ \\
\hline 14. Handover was done at front of the patient. & $\begin{array}{c}29 \\
(17.4)\end{array}$ & $\begin{array}{c}0 \\
(0.00)\end{array}$ & $\begin{array}{c}138 \\
(82.6)\end{array}$ & $\begin{array}{c}44 \\
(26.4)\end{array}$ & $\begin{array}{c}34 \\
(20.4)\end{array}$ & $\begin{array}{c}89 \\
(53.2)\end{array}$ & 47.6 & $.001^{* *}$ \\
\hline $\begin{array}{l}\text { 15. During handover discussions', patients } \\
\text { had the opportunity to participate and/or } \\
\text { listen. }\end{array}$ & $\begin{array}{c}2 \\
(1.2)\end{array}$ & $\begin{array}{c}36 \\
(21.6)\end{array}$ & $\begin{array}{c}129 \\
(77.2)\end{array}$ & $\begin{array}{c}52 \\
(31.1)\end{array}$ & $\begin{array}{c}46 \\
(27.5)\end{array}$ & $\begin{array}{c}69 \\
(41.3)\end{array}$ & 65.7 & $.001^{* *}$ \\
\hline $\begin{array}{l}\text { 16. Further Information I had to seek about my } \\
\text { patient/s take from a nurse or } \\
\text { nurse-in-charge after the handover. }\end{array}$ & $\begin{array}{c}29 \\
(17.4)\end{array}$ & $\begin{array}{c}55 \\
(32.9)\end{array}$ & $\begin{array}{c}83 \\
(49.7)\end{array}$ & $\begin{array}{c}0 \\
(0.00)\end{array}$ & $\begin{array}{c}56 \\
(33.5)\end{array}$ & $\begin{array}{c}111 \\
(66.5)\end{array}$ & 33.0 & $.001^{* *}$ \\
\hline $\begin{array}{l}\text { 17. I can ask any questions about things I did } \\
\text { not understand during handover. }\end{array}$ & $\begin{array}{c}0 \\
(0.00)\end{array}$ & $\begin{array}{c}56 \\
(33.5)\end{array}$ & $\begin{array}{c}111 \\
(66.5)\end{array}$ & $\begin{array}{c}25 \\
(15.0)\end{array}$ & $\begin{array}{c}34 \\
(20.4)\end{array}$ & $\begin{array}{c}108 \\
(64.7)\end{array}$ & 30.4 & $.001^{* *}$ \\
\hline $\begin{array}{l}\text { 18. I have a clear understanding the plan for } \\
\text { the patient/s as a handover outcome. }\end{array}$ & $\begin{array}{c}25 \\
(15.0)\end{array}$ & $\begin{array}{c}34 \\
(20.4)\end{array}$ & $\begin{array}{c}108 \\
(64.7)\end{array}$ & $\begin{array}{c}109 \\
(65.3)\end{array}$ & $\begin{array}{c}58 \\
(34.7)\end{array}$ & $\begin{array}{c}0 \\
(0.00)\end{array}$ & 166.9 & $.001^{* *}$ \\
\hline $\begin{array}{l}\text { 19. During handover, I received adequate } \\
\text { information about nursing care. }\end{array}$ & $\begin{array}{c}0 \\
(0.00)\end{array}$ & $\begin{array}{c}56 \\
(33.5)\end{array}$ & $\begin{array}{c}111 \\
(66.5)\end{array}$ & $\begin{array}{c}59 \\
(35.3)\end{array}$ & $\begin{array}{c}45 \\
(26.9)\end{array}$ & $\begin{array}{c}63 \\
(37.7)\end{array}$ & 73.4 & $.001^{* *}$ \\
\hline 20. Observations of important vital sign. & $\begin{array}{c}109 \\
(65.3)\end{array}$ & $\begin{array}{c}58 \\
(34.7)\end{array}$ & $\begin{array}{c}0 \\
(0.00)\end{array}$ & $\begin{array}{c}57 \\
(34.2)\end{array}$ & $\begin{array}{c}110 \\
(65.8)\end{array}$ & $\begin{array}{c}0 \\
(0.00)\end{array}$ & 32.4 & $.001^{* *}$ \\
\hline $\begin{array}{l}\text { 21. During handover, vital information is often } \\
\text { not given, e.g., allergy, unavailable. }\end{array}$ & $\begin{array}{c}92 \\
(55.1)\end{array}$ & $\begin{array}{c}75 \\
(44.9)\end{array}$ & $\begin{array}{c}0 \\
(0.00)\end{array}$ & $\begin{array}{c}99 \\
(59.2)\end{array}$ & $\begin{array}{c}54 \\
(32.4)\end{array}$ & $\begin{array}{c}14 \\
(8.3)\end{array}$ & 17.6 & $.001^{* *}$ \\
\hline
\end{tabular}

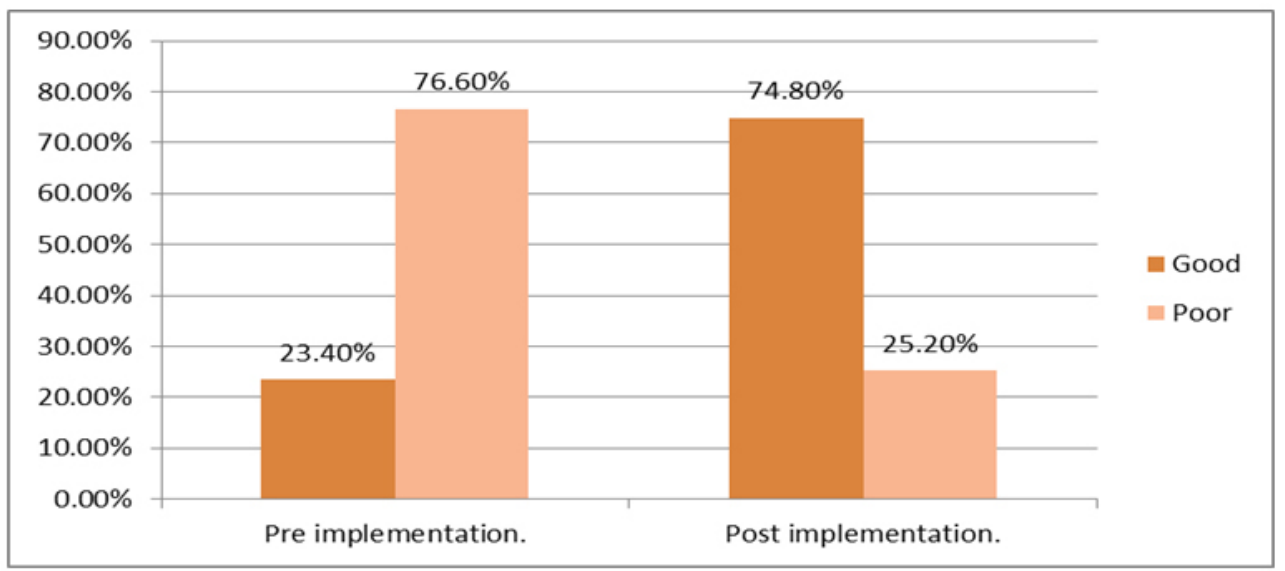

Figure 1. Total of handover attitude throughout pre and post-implementation phases among studied subjects

Table 7. Mean score of nurse satisfaction about clinical handover practice pre and post-implementation phases $(\mathrm{n}=167)$

\begin{tabular}{lllll}
\hline Studied variables & $\begin{array}{l}\text { Pre-implementation } \\
(\text { Mean } \pm \text { SD })\end{array}$ & $\begin{array}{l}\text { Post-implementation } \\
(\text { Mean } \pm \text { SD })\end{array}$ & Paired $\boldsymbol{t}$-test & $\boldsymbol{p}$ value \\
\hline Prior handover process & $12.1 \pm 0.88$ & $14.2 \pm 0.55$ & 26.1 & $.001^{* *}$ \\
During handover process & $25.0 \pm 3.51$ & $33.1 \pm 4.21$ & 19.1 & $.001^{* *}$ \\
After handover process & $6.59 \pm 1.81$ & $8.32 \pm 1.22$ & 10.2 & $.001^{* *}$ \\
Total mean satisfaction & $43.8 \pm 5.20$ & $58.2 \pm 3.21$ & 30.4 & $.001^{* *}$ \\
\hline
\end{tabular}

Note. ${ }^{* *}$ Highly significant 


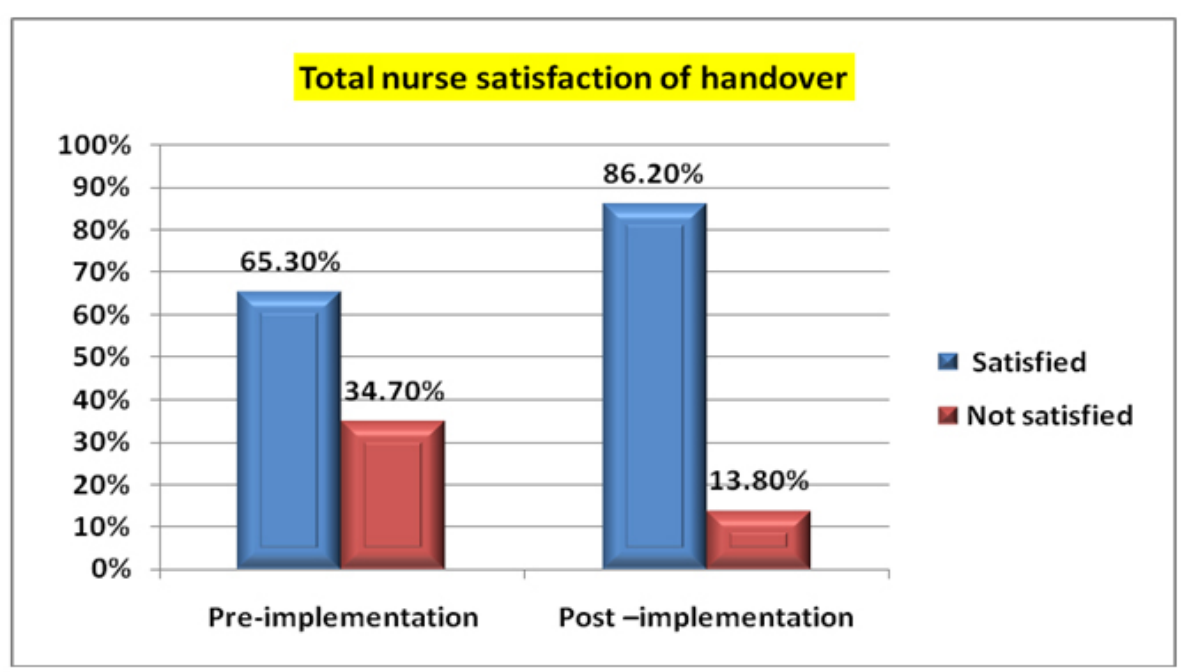

Figure 2. Total nurse satisfaction of handover pre and post-implementation phase

Table 8. Relation between socio-demographic characteristics and nurses clinical handover post intervention $(\mathrm{n}=167)$

\begin{tabular}{|c|c|c|c|c|c|c|}
\hline \multirow{3}{*}{ Socio-demographic } & \multicolumn{4}{|c|}{ Clinical handover } & \multirow{3}{*}{$\chi^{2}$} & \multirow{3}{*}{$p$ value } \\
\hline & \multicolumn{2}{|c|}{ Good $(N=125)$} & \multicolumn{2}{|c|}{ Poor $(\mathrm{N}=42)$} & & \\
\hline & No. & $\%$ & No. & $\%$ & & \\
\hline Age & & & & & 2.59 & .274 \\
\hline - <20 years & 0 & 0.00 & 0 & 0.00 & & \\
\hline - 20-30 years & 58 & 46.4 & 22 & 52.4 & & \\
\hline - $30-40$ years & 60 & 48.0 & 20 & 47.6 & & \\
\hline - $\geq 40$ years & 7 & 5.60 & 0 & 0.00 & & \\
\hline Years of experience & & & & & 80.2 & $.001^{* *}$ \\
\hline - $<5$ years & 0 & 0.00 & 20 & 47.6 & & \\
\hline - 5-10 years & 15 & 12.0 & 11 & 26.2 & & \\
\hline - $10-20$ years & 110 & 88.0 & 11 & 26.2 & & \\
\hline Qualification & & & & & 33.3 & $.001^{* *}$ \\
\hline - Bachelor & 17 & 13.6 & 15 & 35.7 & & \\
\hline - Diploma & 43 & 34.4 & 26 & 61.9 & & \\
\hline - Nursing institute & 65 & 52.0 & 1 & 2.40 & & \\
\hline Departments & & & & & 15.6 & $.001^{* *}$ \\
\hline - Medicine & 56 & 44.8 & 8 & 19.0 & & \\
\hline - Hemodialysis & 18 & 14.4 & 15 & 35.7 & & \\
\hline - Obstetric & 35 & 28.0 & 9 & 21.4 & & \\
\hline - Oncology & 16 & 12.8 & 10 & 23.9 & & \\
\hline
\end{tabular}

Note. ${ }^{* *}$ Highly significant

Figure 2 illustrates total nurse satisfaction of clinical handover pre and post-implementation phase. This figure revealed that there was the highest level of nurses' satisfaction at the post $(86.2 \%)$ than pre $(65.3 \%)$ implementation of SHARD model regarding clinical handover practice.

Table 8 indicates relation between socio-demographic characteristics and clinical handover post-intervention. It was observed that there was a highly statistically significant relation between socio-demographic characteristics except for age and clinical handover post-intervention. The highest relation of nurses $(88.0 \%)$ attitude of clinical handover postintervention which has 10-20 years of experience with qualification as nursing institute especially working at Medicine Department. 
Table 9. Relation between socio-demographic characteristics and nurse satisfaction regarding clinical handover post intervention $(\mathrm{n}=167)$

\begin{tabular}{|c|c|c|c|c|c|c|}
\hline \multirow{3}{*}{$\begin{array}{l}\text { Socio-demographic } \\
\text { characteristics of studied } \\
\text { nurses }\end{array}$} & \multicolumn{4}{|c|}{ Satisfaction of hand over } & \multirow{3}{*}{$\chi^{2}$} & \multirow{3}{*}{$p$ value } \\
\hline & \multicolumn{2}{|c|}{ Satisfied $(N=144)$} & \multicolumn{2}{|c|}{ Not satisfied $(\mathrm{N}=\mathbf{2 3})$} & & \\
\hline & No. & $\%$ & No. & $\%$ & & \\
\hline Age & & & & & 3.75 & .153 \\
\hline$\bullet<20$ & 0 & 0.00 & 0 & 0.00 & & \\
\hline - $20-30$ & 65 & 45.1 & 15 & 65.2 & & \\
\hline - $30-40$ & 72 & 50.0 & 8 & 34.8 & & \\
\hline$\cdot \geq 40$ & 7 & 4.90 & 0 & 0.00 & & \\
\hline Years of experience & & & & & 54.9 & $.001^{* *}$ \\
\hline$\bullet<5$ & 10 & 6.90 & 10 & 43.5 & & \\
\hline - $5-10$ & 15 & 10.4 & 11 & 47.8 & & \\
\hline - $10-20$ & 119 & 82.6 & 2 & 8.70 & & \\
\hline Qualification & & & & & 4.23 & .121 \\
\hline - Bachelor & 24 & 16.7 & 8 & 34.8 & & \\
\hline - Diploma & 61 & 42.4 & 8 & 34.8 & & \\
\hline - Nursing institute & 59 & 40.9 & 7 & 30.4 & & \\
\hline Departments & & & & & 1.61 & .658 \\
\hline - Medicine & 56 & 38.9 & 8 & 34.8 & & \\
\hline - Hemodialysis & 27 & 18.8 & 6 & 26.1 & & \\
\hline - Obstetric & 37 & 25.7 & 7 & 30.4 & & \\
\hline - Oncology & 24 & 16.7 & 2 & 8.70 & & \\
\hline
\end{tabular}

Note. ${ }^{* *}$ Highly significant

Table 9 shows relation between socio-demographic characteristics and satisfaction regarding clinical handover postintervention. As indicated from the table, there was a highly statistically significant relationship between satisfaction of clinical handover post-intervention and years of experience except for age, qualification, and departments with no statistically significant differences.

\section{Discussion}

Provision of safe and proper health care is very important to patients' health. At this time, a wide range of safety issues has confronted the healthcare distribution, and therefore, many individual and managerial strategies have been established for supporting patient safety. ${ }^{[14]}$ Intended communication processes have been established as a standard, indications for good practice for handovers is not known. The intent of the patient handover is to provide for continuity of care, to address changes in patient condition and to track and to communicate patient response to the care that is being provided. ${ }^{[15]}$ Therefore, this study aimed to explore the effect of implementing a SHARED and its influence on nurses' satisfaction.

Before discussing the results, attention to socio-demographic Published by Sciedu Press characteristics of the studied subjects should be reviewed. The mean age of studied nurses were $(31.6 \pm 6.48)$, and the majority of the studied subjects $(95.8 \%)$ were from 20 to 40 years old. Furthermore, the majority of subjects (72.4) had from 10-20 years of experience with the mean $(11.3 \pm 6.65)$ of 11 years. Regarding qualifications, the highest percentage of the studied subjects (41.3\%) had a diploma in nursing. The majority of subjects (38.3\%) were from the Medicine Department.

The present study indicated that regarding levels of knowledge about handover practices pre and post implementation phases among studied subject. It was observed that levels of studied subjects' total knowledge were significantly improved post than pre-implementation phases at $p \leq .05$. It was observed that levels of studied subjects' total knowledge was significantly improved post-implementation than preimplementation at $p \leq 0.05$. And also, the level of clinical handover knowledge was low (76.6\%) pre-implementation of a structured model of clinical handover (SHARED). Otherwise, the level of clinical handover knowledge was high (74.8) post-implementation using the SHARED. This result was not similar to those ${ }^{[16,17]}$ who found that using a mnemonic did not improve information retaining by emer- 
gency department staff ( $56.6 \%$ data retaining using unstructured handovers vs. $49.2 \%$ using structured handovers) or information recall. Adding a handover was not improved by an intervention to enhance paramedic communication skills. ${ }^{[18]}$

The study finding revealed that the method of handover showed no changed at pre $\&$ post-implementation of the structured model and all nurses used oral and written method. These results were not congruent with Delrue, ${ }^{[15]}$ who found that the frequent method which the RN's used was a verbal report byways of the telephone at $81.48 \%$. Percentage of using the electronic medical record was $44.44 \%$ and Emergency Department admission handovers "SBAR" tool (3.7\%) only being used.

Concerning the time of handover, it takes more time (16-20 minutes pre-implementation), but after the implementation, it takes less time from nursing staff. This result was similar to $\operatorname{Kerr}^{[8]}$ who stated that the current handover practices were time-consuming, required patient participation and varied in styles. In spite of these undesirable perceptions, it was also well-known that $82 \%$ of the staff (153 RNs from 23 wards) stated they wanted the modification of the handover style used in the current practice.

Additionally, there was a statistically significant improvement of studied nurses concerning the most items of clinical handover pre to post-implementation of structured clinical handover at $p \leq .05$. Nurses reported that receiving information was up to date. (pre: $0.0 \%$; post: $77.8 \% ; p<.001$ ) This result was similar to Delrue ${ }^{[15]}$ who stated that updated the organization's work depends on the policy of handovers communication that had written in 2007.

Additionally, nurses reported that "during handover discussions", patients had the opportunity to participate and/or listen (pre: $1.2 \%$; post: $31.2 \%$; $p<.001$ ). Studied subjects were less able to report that "observations of important vital sign are repeatedly absent from nursing handover" (pre: 65.3\%; post: $34.2 \% ; p<.001$ ) after structured handover methods had been implemented. This result is in the same line with $\mathrm{Kerr}^{[8]}$ who indicated that during handover discussions, patients had the opportunity to participate and listen (pre: $42.2 \%$; post: $80.7 \% ; p<.001$ ) at an improved after structured handover methods had been implemented. Studied subjects were less able to report that observations of important vital signs are repeatedly absent from nursing handover (pre: $50.0 \%$; post: $32.2 \% ; p=.022$ ) after implementation of the structured handover approach.

The finding of the present study revealed that using effective communication skills' during handover (pre: 42.5\%; post: $77.8 \% ; p<.001)$. This result was congruent with Smeulers ${ }^{[19]}$ who stated that communication gaps during handover can cause several problems such as medication errors, in appropriate treatment, diagnoses, and delays of care omission.

Concerning total attitude of clinical handover pre and postimplementation phase among studied subjects, it was observed that there was an improvement of nurse clinical handover post-implementation of SHARED framework among studied subjects $(74.80 \%)$ and had a good level than pre $(34.40 \%)$ implementation phases. This result was in the same line with $\operatorname{Kerr}^{[8]}$ who stated that nursing care activities, documentation, and communication of vital information to nurses on the receiving shift were improved after implementation of a new handover model (SBAR).

Regarding implementation of structured model (SHARED framework) on nurse's satisfaction, the finding revealed that there was the highest level of nurse satisfaction $(86.2 \%)$ at the post than pre $(65.3 \%)$ implementation phase. This result was not similar to Johnson ${ }^{[20]}$ who stated that an integrated system has been applied with progressive outcomes of improved nurse satisfaction with handover, nurses were actually knowledgeable about all patients, had improved patient assignments and better patient information for all health specialists. With bedside handoff, additional benefits were engaging the patient in care collaboration and completing a visual safety assessment of the patient environment.

Furthermore, relationships between socio-demographic characteristics and nurse of clinical handover post-intervention showed that the highest relation between nurses $(88.0 \%)$ of clinical handover post-intervention which had 11-20 years of experience with qualification as nursing institute especially working at Medicine department. This result was in the same line with O'Connell ${ }^{[13]}$ who stated that there were alterations in perceptions recognized on the basis of years of experience and worked hours number. It is exciting to note some difference between the nursing staff from the ED and the in-patient units, especially the years of experience and the maximum level of education accomplished. The in-patient staff stated that the highest percentage of inexperience with $64.71 \%$ having five years or less experience as an $\mathrm{RN}$, in a comparison to $25 \%$ of the studying staff of Emergency Department. Additionally, in-patient nursing staff had the highest percentage of staff prepared at the baccalaureate level with $52.94 \%$ in comparison to $20 \%$ of Emergency Department staff.

\section{Conclusions}

According to the results of the present study, it was concluded that nurses' levels of total knowledge regarding 
practices of the current clinical handover were poor at preimplementation and improved after implementation of structured model as SHARED. Additionally, there was an improvement of clinical handover attitude post-implementation of SHARED framework among studied subjects and had a good level of attitude than pre-implementation phases. Also, there was highest level of nurses' satisfaction at the post than pre-implementation of SHARD model regarding clinical handover practice.

\section{Recommendations}

- Replication of the study on a large probability sample from different settings is required to allow generalizability of the findings.

- Ongoing educational sessions for nurses and periodic refresher training courses should be provided in or- der to keep nurses updating knowledge and practice regarding the structured and standardized model.

- Adoption of the standardized and structured model as a practice guideline for conducting handover for various categories of nurses in different settings.

- Developing periodic follow-up is required to provide more information on the lasting impact of the model.

- Strict observation of nurses' performance on utilization of structured and standardized model and correction of poor practices from their supervisors.

- Hospital management policy should be implemented a SHARED structure in documentation system.

\section{CONFLicts OF InTEREST Disclosure}

The authors declare they have no conflicts of interest.

\section{REFERENCES}

[1] Athwal P, Fields W, Wagnell E. Standardization of change-ofshift report. Journal of Nursing Care Quality. 2009; 24: 143. PMid: 19287253. https://doi.org/10.1097/01.NCQ.00003 47451.28794 .38

[2] Foster S, Manser T. The effects of patient handoff characteristics on subsequent care: A systematic review and areas for future research. Academic Medicine. 2012; 87: 1105-1124. PMid: 22722354. https://doi.org/10.1097/ACM.0b013e31825cfa69

[3] Staggers N, Clark L, Blaz JW, et al. Why patient summaries in electronic health records do not provide the cognitive support necessary for nurses' handoffs on medical and surgical units: Insights from interviews and observations. Health Informatics Journal. 2011; 17: 209-223. PMid: 21937463. https://doi.org/10.1177/146045 8211405809

[4] Performance, Quality and Rural Health, Victorian Government, Department of Health. June 2014.

[5] Patterson E, Wears R. Patient handoffs: Standardized and reliable measurement tools remain elusive. Joint Commission Journal on Quality \& Patient Safety. 2010; 36: 52-61. https ://doi .org/10 .1016/S1553-7250(10)36011-9

[6] Australian Medical Association. Canberra: AMA; 2006. Safe handover: safe patients. Guidance on clinical handover for clinicians and managers. In Pascoe H, Gill SD, Hughes A, McCall-White M. Clinical handover: An audit from Australia. Australas Med J. 2014 Sep 30; 7(9): 363-71. PMid: 25324901.

[7] Klim S, Kelly AM, Kerr D, et al. Developing a framework for nursing handover in the emergency department: An individualised and systematic approach. Journal of Clinical Nursing. 2013; 22: 2233-2243. PMid: 23829405. https://doi.org/10.1111/jocn. 12274

[8] Kerr D, Klim S, Mckay K, et al. Attitudes of emergency department patients about handover at the bedside. Journal of Clinical Nursing. 2016.

[9] Australian Institute of Health and Welfare. Safe handover: Safe patients; guidelines on clinical handover for clinicians and managers. 2006. Available from: http://www.ama.com.au/web.nsf/doc /WEEN-6XFDKN/pdf

Published by Sciedu Press
[10] Australian Commission on Safety and Quality in Health Care (Acsqhe). Windows into Safety and Quality in Health Care. ACSQHC, Sydney. 2008. Available from: http://www . safetyandquality .gov. au/wpcontent/uploads/2008/01/Windows-into-Saf ety-and-Quality-in-Health-Care-2008-FINAL.pdf

[11] Carroll J, Williams M, Gallivan T. The Ins and Outs of Change of Shift Handoffs between Nurses: a Communication Challenge. BMJ Quality \& Safety. 2012; 586-593. PMid: 22328456. https : //doi.org/10.1136/bmjqs-2011-000614

[12] Morsy M. The Effectiveness of Implementing Clinical Supervision Models on Head Nurses' Performance and Nurses' Job Satisfaction. Benha University Hospital Faculty of Nursing, Benha University; 2014.

[13] O'Connell B, MacDonald K, Kelly C. Nursing handover: It's time for a change. Contemporary Nurse. 2008; 30: 2-11. PMid: 19072186. https://doi.org/10.5172/conu.673.30.1.2

[14] World Health Organization. Communication during patient hand-overs. Patient Safety Solutions. 2009; 1(3). Available from: http://www. who.int/patientsafety/solutions/pa tientsafety/en/index.html

[15] Delrue K. Translating an evidence based protocol for nurse to nurse shift handoffs. Worldviews on Evidence Based Nursing. 2013; 7: 59-75.

[16] Talbot R, Bleetman A. Retention of information by emergency department staff at ambulance handover: do standardised approaches work? Emerg Med J. 2007; 24: 539-42. In Wood, K., Crouch, R., Rowland, E., \& Pope, C. Clinical handovers between pre-hospital and hospital staff: Literature review. Emergency Medicine Journal. 2014

[17] Wood K, Crouch R, Rowland E, et al. Clinical handovers between prehospital and hospital staff: Literature review. Emergency Medicine Journal. 2014.

[18] Shields S, Flin R. Paramedics' non-technical skills: a literature review. Emerg Med J. 2012; 30: 350-4. PMid: 22790211. https: //doi.org/10.1136/emermed-2012-201422

[19] Smeulers M, Van Tellingen IC, Lucas C, et al. Effectiveness of different nursing handover styles for ensuring continuity of information in hospitalised patients. Cochrane Database of Systematic Reviews. 
2012(7): CD009979. https://doi.org/10.1002/14651858.C D009979

[20] Johnson M, Sanchez P, Zheng C. The impact of an integrated nurs- ing handover system on nurses' satisfaction and work practices. J Clin Nurs. 2016; 25(1-2): 257-68. PMid: 26769213. https: //doi.org/10.1111/jocn. 13080 